\title{
Trends in prevalence and acceptance of workplace smoking bans among indoor workers in South Australia
}

\author{
Melanie Wakefield, Lyn Roberts, Neville Owen
}

\begin{abstract}
Objective-To compare the reported prevalence and acceptance of bans on smoking in the workplaces of a representative sample of adults in South Australia between 1989 and 1994.

Design-Independent cross-sectional representative population surveys.

Setting-South Australian population.

Participants-Adults who indicated they were employed mainly indoors, for the years 1989 (875 respondents), 1991 (1472), 1992 (1288) and 1994 (1273).

Main outcome measures-Percentage reporting total bans on smoking at work; percentage reporting compliance with bans all or nearly all the time; percentage reporting preference for total bans at work.

Results-The percentage of indoor workers subject to a total ban on smoking at work increased from $32 \%$ in 1989 to $62 \%$ in 1994 and preference for a total ban increased during the same period from $26 \%$ to $52 \%$. Reported compliance with restrictions and bans was very high. In $1994,16 \%$ of workers still had no restrictions on smoking at work, but only $3 \%$ preferred this arrangement.

Conclusion-The data suggest that smoking bans are now the norm for indoor workers and that further gains in promoting and supporting workplace bans will be made by directing efforts at smaller workplaces, where unrestricted smoking is most prevalent.
\end{abstract}

(Tobacco Control 1996;5:205-208)

Keywords: smoking ban; workplace; prevalence; South Australia

Epidemiology Unit, South Australian

Health Commission Adelaide, South Australia

M Wakefield

South Australian

Smoking and Health

Project, Adelaide,

South Australia

L Roberts

Department of Human Movement Science,

Deakin University,

Melbourne, Victoria

N Owen

Correspondence to:

Dr M Wakefield, Behavioural Epidemiology Unit, South Australian Health

Commission, PO Box 6

Rundle Mall, South Australia

5000, Australia; email:

maw@hc2.health.sa.gov.au

\section{Introduction}

In Australia and other countries, employers have a moral and legal obligation to provide workplaces that are safe and healthy for their staff. With increasing appreciation of the health hazards posed by passive smoking, workplace restrictions on smoking have been advocated by health agencies. In 1989, a South Australian study found that $32 \%$ of indoor workers reported a total ban on smoking at their place of work, with a further $33 \%$ reporting a partial ban applying to their usual workstation. ${ }^{1}$ Since that time, there have been significant developments in Australia which have increased the desire by employers to minimise their risk of liability from passive smoking-related diseases. In February 1991, an Australian court ruling, subsequently upheld under appeal in
December 1992, concluded that passive smoking causes lung cancer, asthma attacks, and of respiratory disease in children. ${ }^{23}$ Within a short time of the ruling, health agencies involved in tobacco control activities were besieged by enquiries from concerned employers, aware that their duty of care to provide safe workplaces for employees would be considered to be violated if they continued to allow unrestricted smoking at work. In May 1992, an Australian woman, Leisel Scholem, was awarded A \$85000 damages for disease attributable to environmental tobacco smoke exposure at her workplace. ${ }^{4}$ This was the first time that an Australian jury supported such a damages claim against an employee. Each of these events received significant media coverage.

Apart from these legal rulings, public education efforts about passive smoking have intensified. The South Australian Smoking and Health Project (SASHP) is charged with the role of providing public education about smoking in South Australia. (It is a joint initiative of the Anti-Cancer Foundation and the National Heart Foundation, with funding from Foundation South Australia, which is the health promotion foundation created from an increase in the state tobacco licence fee to fund health promotion programmes and replace tobacco sponsorship of sport and the arts with health promotion messages.) During 1992 and 1993, the SASHP highlighted passive smoking as a theme in its campaigns, with television, radio, and print advertisements, education booklets and posters. ${ }^{5}$ Within an environment that is now more supportive of people's rights to breathe smoke-free air, South Australian campaigns over the past few years have presented passive smoking as an issue for both non-smokers and smokers. The SASHP has also been involved in assisting workplaces to introduce restrictions on smoking. In 1992, two brochures targeting small business were produced in collaboration with the South Australian Health Commission and more than 10000 brochures were distributed throughout businesses in South Australia. The SASHP also responded to telephone enquiries about smoking in the workplace during the passive smoking media campaigns.

These developments raise questions about the extent to which bans on smoking in the workplace have increased in prevalence, how well they are complied with, and their level of acceptance. In addition, further progress in introducing workplace bans requires an identification of the types of workplaces that are still not subject to any restrictions. In the context of 
monitoring indices of smoking at the population level, these issues have been of interest to SASHP and the data from a series of comparable population surveys are reported here.

\section{Methods}

Data for the year 1989 were collected as part of an August survey of South Australians undertaken by the Australian Bureau of Statistics. ${ }^{1}$ A sample of 1929 respondents aged 15 years or older, of which 875 were employed mainly indoors, were compared with samples from subsequent population surveys which used the same survey methodology and a standard set of questions.

Data from the years 1991, 1992, and 1994 were collected using independent crosssectional samples, as part of an annual Omnibus Survey about health issues, which involved multistage, systematic, clustered area samples of households in South Australia. Like the 1989 survey, the sampling frame for each subsequent year was based upon the Australian Bureau of Statistics Census collector's districts and included private households, with $75 \%$ of the sample from the Adelaide metropolitan area and the remainder from country centres with a population of 1000 or more. At each selected household, one person aged 15 years or older was selected for interview, being the person whose birthday was due next. Interviews were conducted in the respondents' homes by trained interviewers, with at least five callback visits being made to each household in an attempt to obtain an interview if the selected respondent was not at home. Data were weighted by household size, age, gender, and geographical location to the South Australian adult population for that year. The 1989 survey was undertaken in August, whereas surveys in all other years were conducted in October and November.

Although each survey covered a range of health issues, over four years $(1989,1991$, 1992, and 1994), a standard set of questions about smoking in the workplace were asked of people who were in paid employment and who indicated that they worked mainly indoors. First, all respondents in paid work were asked to describe the extent of smoking restrictions at their workplace. Response options were coded as: a total ban; a partial ban, including a ban applying to their usual work station (this included respondents who indicated there was a smoking room available or that smoking was allowed in other parts of their workplace); or no ban applying to their usual work station (this included no restrictions on smoking at all and cases where restrictions applied in some areas, but not at their usual work station). In

Table 1 Characteristics of indoor workers by year of survey

\begin{tabular}{lllll}
\hline & $\begin{array}{l}1989 \\
(n=875)\end{array}$ & $\begin{array}{l}1991 \\
(n=1472)\end{array}$ & $\begin{array}{l}1992 \\
(n=1288)\end{array}$ & $\begin{array}{l}1994 \\
(n=1273)\end{array}$ \\
\hline Male (\%) & 52.2 & 54.1 & 51.4 & 51.8 \\
Mean age (SD) & $34.6(11.6)$ & $36.6(11.7)$ & $36.6(11.6)$ & $36.4(11.5)$ \\
Smokers (\%) & 29.3 & 25.8 & 28.9 & 30.5 \\
Employed fulltime (\%) & NA & 72.3 & 70.4 & 70.9
\end{tabular}

$\mathrm{NA}=$ not available.
1994, respondents were also asked to indicate, in their opinion, how well smokers observed the restrictions on smoking at work. Response options were: nearly all or all of the time; some of the time; and none of the time.

Respondents were then asked to nominate which statement best described their opinion about allowing smoking at their workplace. Response options were: should not allow it anywhere at work; should allow it in special areas; or should allow it everywhere.

Descriptors including age, gender, and smoking status were also collected in each year. Respondents in the 1994 survey were also asked which of the following described the size of their company or organisation: small (1-20 employees), medium (21-50 employees), large ( $>50$ employees), or self-employed/just yourself. Respondents were also asked to indicate whether they worked for an Australian federal government employer, a state government employer, or a non-government employer. These descriptors permitted a characterisation of the type of employees still not subject to restrictions on smoking at work in 1994.

Comparisons between proportions were undertaken by means of $\chi^{2}$ tests. Statistical analysis was undertaken using SPSS version 6.1 .

\section{Results}

The response rate in 1989 was $89 \%$, and for each subsequent year was $73 \%$ (1991), $72.9 \%$ (1992), and $72.4 \%$ (1994). In 1989, 875 respondents to the survey were identified as being employed and mainly working indoors. The corresponding number of such respondents for subsequent survey years was 1472 in 1991,1288 in 1992, and 1273 in 1994. Table 1 shows the characteristics of indoor workers in each survey. There was no statistically significant difference between survey respondents across years, except with respect to smoking prevalence $\left(\chi^{2}=8.0, \mathrm{df}=3, \mathrm{P}=0.05\right)$.

In each year, fewer than $1 \%$ of indoor workers were not able to nominate the arrangements regarding smoking restrictions at their workplace and these were excluded from subsequent analyses. Figure 1 shows the increase in the prevalence of workplace smoking restrictions in the six-year period over which the four surveys were conducted. Overall, there was an approximate doubling of the percentage of indoor workers who were subject to a total ban on smoking at work, from $32 \%$ in 1989 to $62 \%$ in 1994 . Most of this increase occurred between 1989 and 1991. However, since 1991, there continued to be a significant increase in the percentage who reported a total ban $\left(\chi^{2}\right.$ trend=8.6, $\left.\mathrm{df}=1, \quad \mathrm{P}<0.01\right)$, with commensurate declines in the percentage who reported no restrictions at their usual work station. In $1994,16 \%(n=200)$ had no smoking restrictions at their normal work station. In 1994, workers who were more likely to report having no restrictions at their workplace included smokers $\left(\chi^{2}=27.4, \mathrm{df}=2, \mathrm{P}<0.001\right)$ (and of smokers, those who smoked more than the median of 14 cigarettes per day $\left(\chi^{2}=11.2\right.$, 
$\mathrm{df}=2, \quad \mathrm{P}<0.004))$, males $\left(\chi^{2}=25.5, \mathrm{df}=2\right.$, $P<0.001)$, those employed in small workplaces (less than 20 people) compared with larger workplaces $\left(\chi^{2}=126.6, \mathrm{df}=1, \mathrm{P}<0.001\right)$, those who were self-employed rather than employed by others $\left(\chi^{2}=44.9, \mathrm{df}=1, \mathrm{P}<0.001\right)$, and those who were employed in non-government organisations rather than by state or federal government agencies $\left(\chi^{2}=38.4, \mathrm{df}=2\right.$, $\mathrm{P}<0.001)$. Of particular note, among those employees in large workplaces (more than 50 employees), only $7 \%$ had no restrictions on smoking, compared with $10 \%$ in mediumsized workplaces (21-50 employees), $27 \%$ in small workplaces (less than 20 employees), and $40 \%$ of self-employed people.

In 1994, among those reporting total bans, $93 \%$ thought that the ban was observed all of the time, and a further $6 \%$ thought it was observed most of the time. For those workers where smoking was not permitted at their usual work station but where smoking was allowed in other parts of the workplace, $87 \%$ were of the view that the restrictions were adhered to nearly all of the time and a further $11 \%$ thought that this was the case some of the time. Reported compliance all or nearly all the time with total bans was $89 \%$ among employees of state government departments, 93\% among non-government employees and $97 \%$ among federal government employees $\left(\chi^{2}\right.$ $=5.4, \mathrm{df}=2, \mathrm{P}<0.07)$.

All indoor workers were also asked for their opinion about smoking at work. Figure 2 indicates an increase in the percentage of indoor workers who express a preference for a total ban, from $26 \%$ in 1989 to $52 \%$ in 1994 , with most of the increase occurring between 1989 and 1991 . In 1994, only $3 \%$ of indoor workers were of the view that smoking should be allowed anywhere at work. Preference for a total ban was significantly more likely to be reported in 1994 among those who themselves were subject to such bans at their own workplace $\left(\chi^{2}=22.8, \quad \mathrm{df}=1, \quad \mathrm{P}<0.001\right)$. However, among those with no restrictions on smoking, $21 \%$ were of the view that there should be a total ban and a further $58 \%$ thought there should be restrictions on where people could smoke. Only $20 \%$ of those who worked under conditions of unrestricted smoking were happy with the status quo, two-thirds of whom were smokers.

\section{Discussion}

A strength of the study is that standard questions and sampling procedures were used, which facilitates comparison across years. However, a much higher response rate was achieved in 1989 than in subsequent years, due to the survey being conducted by the Australian Bureau of Statistics, which traditionally achieves such high response rates because they have a legal authority to collect interview survey data. Despite this difference, the samples were broadly comparable across years.

Clearly, since 1989 there have been marked increases in the prevalence of workplace smoking bans, to the extent that a total ban on

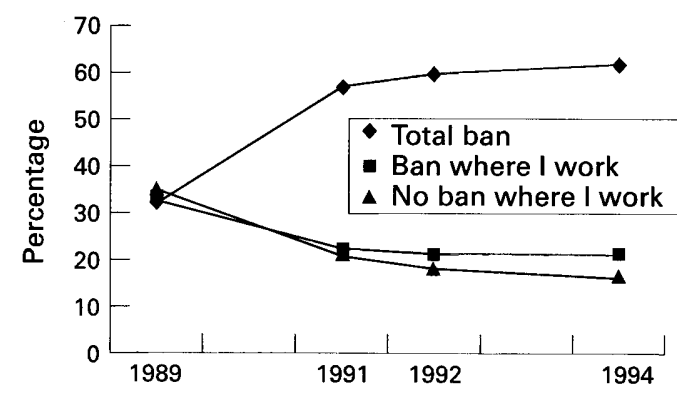

Figure 1 Type of smoking restriction at work, by year (indoor workers only)

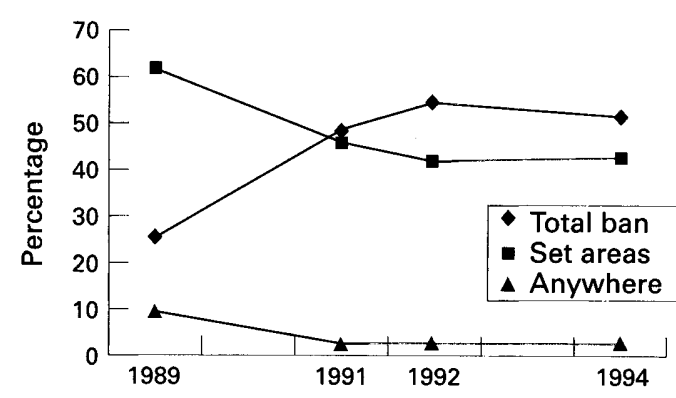

Figure 2 Opinion about workplace smoking restrictions, by year (indoor workers only)

smoking now represents the norm for most indoor workers. This is a significant public health outcome, because non-smokers are only effectively protected from environmenta tobacco smoke where there is a total ban on smoking at their workplace. ${ }^{6}$ In addition, there is likely to be a public health benefit for smokers, since previous studies have shown that the introduction of workplace smoking bans are associated with a reduction in daily smoking rate between two and five cigarettes per day. ${ }^{7-9}$ This is linked to the fact that such smokers have fewer opportunities to smoke during the work day, and do not compensate during breaks for the amount that they would have smoked, had bans not been in force.

It is evident that most of the increase in prevalence of workplace smoking bans occurred between August 1989 and November 1991, although there has been a continuation of this trend up to November 1994. The Morling ruling, handed down in February 1991, is likely to have been an important factor underlying this increase, also documented in other Australian States, such as New South Wales and Victoria. ${ }^{1011}$ In 1992, the Scholem case and the passive smoking theme of the Quit campaigns in 1992 and 1993 may have provided additional incentive for the sustained introduction of bans. In Victoria, where comparable population surveys have been conducted, $59 \%$ of indoor workers had reported total bans on smoking at their place of work in $1992 .{ }^{11}$ This is almost identical to the $60 \%$ of indoor workers so reporting in South Australia in 1992. It is likely that these trends apply across Australia, rather than pertaining to one or two states.

During the survey period, there was also an increase in acceptance of bans on smoking at work, such that in 1994 more than half of indoor workers preferred total bans and only $3 \%$ preferred no restrictions. Most of the 
increase in preference for total bans occurred between 1989 and 1991, concomitant with the increase in prevalence of total bans. A number of studies have suggested that once introduced, workplace smoking bans gain in acceptance by staff and the present findings are consistent with these studies. ${ }^{12-14}$ It may be that the negative consequences of smoking bans anticipated by staff do not come about, or may be less severe than expected. An Australian study found that where bans are introduced in consultation with staff and where management actively encourages compliance, high levels of acceptance and compliance can be achieved for total bans. ${ }^{14}$ In the main, the present data showed that compliance with bans was perceived to be very high, although compliance was greater with total, than with partial, bans. It is interesting to note that compliance was reported as higher among federal government employees, who were the first to see the introduction of total bans in 1988 .

There were still $16 \%$ of indoor workers who, in 1994, reported no restrictions on smoking at their usual work station. Of these, only one in five were in fact supportive of this arrangement (two-thirds of whom were smokers) and most expressed a preference for either a total ban or other restrictions. There is thus considerable support for change in this subgroup of workers.

Workers who continue to experience unrestricted exposure to environmental tobacco smoke at work are mainly employed in small workplaces, or are self-employed. For those smokers who work alone, passive smoking may not be an issue. However, previous studies have also suggested that smaller workplaces are more likely to have unrestricted smoking ${ }^{15} 16$ and it may be that these worksites have a less developed occupational health presence. This information is helpful for targeting proactive efforts to support the introduction of bans. These workers may represent a group who are likely to be very resistant to introducing smoking bans and for whom legislation might be the only strategy to effect change. These findings are supported by ad hoc evidence from callers to SASHP's telephone quit smoking service who are non-smoking employees in small workplaces, and who describe their reticence to take on the management who smoke, in pursuit of a non-smoking workplace.

The respondents to this survey were drawn from a representative population survey and as such, the study gives a picture of the extent to which workplace bans apply to the population of workers. In contrast, other surveys have used worksites as a sample frame, and generate estimates of what percentage of companies have workplace smoking bans. Often, the sampling frame for such surveys are large companies, which are viewed as opinion leaders in the business sector. Such surveys typically have managers or occupational health personnel as respondents, who can accurately report on the company's policy with respect to passive smok- ing, give an account of the factors leading to the introduction of the policy, and provide insights into problems with compliance. ${ }^{1017}$ However, these surveys typically do not provide a picture of the extent to which employees in smaller worksites are subject to such bans. This is an important omission, because small workplaces employ a substantial percentage of workers and have a less developed occupational health presence. In our survey, $30 \%$ of indoor workers were employed in workplaces with fewer than 20 employees and a further $8 \%$ were self-employed. In Australia as a whole, about $38 \%$ of employees are employed in workplaces of fewer than 20 people. $^{18}$

In summary, there have been significant gains in protecting indoor workers from exposure to environmental tobacco smoke at work. Further efforts to encourage and support the continued introduction of total bans will need to focus especially upon smaller workplaces. Those workplaces that have not yet introduced restrictions on smoking need to be aware that they are in a diminishing minority. As noted by Borland and Mullins, in the event that such employers were to face litigation on passive smoking issues, this could be part of a case to demonstrate negligence. ${ }^{11}$ Employers ought to be aware that, in the vast majority of cases, a total ban is the most effective way to protect the health of their staff.

1 Wakefield M, Wilson D, Owen N, Esterman A, Roberts L. Workplace smoking restrictions, occupational status and 34:693-7.

2 Chapman S, Woodward S. Australian Court rules that passive smoking causes lung cancer, asthma attacks and respiratory disease. $B M F$ 1991;302:943-5.

3 Everingham R, Woodward S (eds). Tobacco litigation: the case against passive smoking. Sydney: Legal Books, 1991.

4 Smoking bans to hit S.A. The Advertiser (Adelaide, South Australia) 1992 May 28:1-2.

5 South Australian Smoking and Health Project. Ouit evaluation report number 4, 1992-1994. Adelaide, SASHP, Febrution report

6 Borland R, Pierce JP, Burns DM, Gilpin E, Johnson M, Bal $D$. Protection from environmental tobacco smoke in California: the case for a smoke-free workplace. $\mathscr{f} A M A$ 1992;268:749-52.

7 Borland R, Chapman S, Owen N, Hill D. Am f Public Health 1990;80:178--80.

8 Borland R, Owen $\mathrm{N}$, Hocking $\mathrm{B}$. Changes in smoking behaviour after a total workplace smoking ban. Aust $\mathcal{F}$ Public Health 1991;15:130-4.

9 Jeffery RW, Kelder SH, Forster JL, French SA, Lando HA, Baxter JE. Restrictive policies in the workplace: effects on prevalence and cigarette consumption. Prev Med 1994; 23:78-82.

10 Palin $M$, Young $M$. The impact of smoking litigation on Australian workplaces. Tobacco Control 1994;3:78-9.

11 Borland R, Mullins R. The increasing prevalence of workplace smoking bans in Victoria. $\mathcal{F}$ Occup Health Safety-Aust NZ 1994;10:35-40.

12 Rosenstock IM, Sterggachis A, Heaney C. Evaluation of smoking prohibition policy in a health maintenance smoking prohibition policy in a health maintenar

13 Borland $R$, Owen $N$, Hill D, Chapman S. Changes in the acceptance of workplace smoking bans following their implementation: a prospective study. Prev Med 1990;19: 314-22.

14 Hocking B, Borland R, Owen N, Kemp G. A total ban on workplace smoking is acceptable and effective. $f$ Occup Med 1991;33:163-7.

15 Metcalf CA, Yach D. Smoking policies in the workplace in the Western Cape. South African Med f 1992;81:23-6.

$16 \mathrm{Koh}$ YH, Voo YO, Yong LS. Smoking restrictions in private workplaces in Singapore. Singapore Med $f$ 1994;35:250-6.

17 Richmond R, Heather N, Holt P, Hu W. Workplace policies and programs for tobacco, alcohol and other drugs in Australia. Canberra, National Campaign against Drug Abuse, 1992.

18 Australian Bureau of Statistics. Small business in Australia. Canberra: Australian Bureau of Statistics, 1995. Catalogue no. 1321.0 